\title{
Analisis Perbandingan Kapasitas Balok Komposit Baja-Beton dengan Steel Headed Stud dan UNP Stud
}

\author{
(Comparative Analysis of the Capacity of Steel-Concrete Composite Beams \\ with Steel Headed Stud and UNP Stud)
}

\author{
Gati Annisa Hayu*), Ahmad Mifta A, Syamsul A. \\ Program Studi Teknik Sipil, Fakultas Perencanaan Infrastruktur, Universitas Pertamina \\ Jl. Teuku Nyak Arief Jakarta 12220 \\ ${ }^{*}$ Penulis Korespondensi E-mail: gati.hayu@universitaspertamina.ac.id
}

\begin{abstract}
Abstrak
Penghubung geser atau stud memiliki peranan penting dalam menghasilkan perilaku komposit baja-beton. Terdapat dua jenis stud yang direkomendasikan, yaitu steel headed stud atau paku berkepala dan UNP stud atau kanal. Penelitian ini menganalisis perbandingan kapasitas balok komposit baja-beton dengan penghubung geser jenis steel headed stud dan UNP stud. Pemodelan menggunakan program elemen hingga dipilih sebagai metode dalam analisis perilaku non-linier. Luas permukaan kedua jenis penghubung geser dibuat sama sehingga kuat nominal, jumlah, dan jarak pemasangan penghubung geser pun juga akan sama untuk kedua jenis pemodelan ini. Kapasitas yang ditinjau meliputi tegangan pada balok baja WF, tegangan pelat beton, tegangan pada stud, konsentrasi tegangan pada balok baja dan pelat beton, serta defleksi pada balok komposit. Sebelum melakukan pemodelan dengan program elemen hingga, proses desain sesuai SNI 1727:2015 dilakukan terlebih dahulu untuk menentukan dimensi struktur yang akan digunakan. Validasi diperlukan untuk melihat tingkat keakuratan pemodelan yang dilakukan. Metode validasi dilakukan dengan membandingkan nilai tegangan lentur pada serat bagian bawah dan atas balok komposit baja-beton. Persentase pemodelan mencapai 86,95\% untuk model steel headed stud dan $87,4 \%$ untuk UNP stud. Hasil pemodelan menunjukkan bahwa balok komposit dengan UNP stud memilik kapasitas yang lebih baik karena menghasilkan nilai tegangan-tegangan dan defleksi yang lebih kecil. Tegangan lentur balok baja $U N P$ stud dan steel headed stud adalah 19,129 MPa dan 19,556 MPa (perbedaan 2,18\%). Tegangagan lentur pelat beton UNP stud dan steel headed stud adalah 1,21 MPa dan 1,194 MPa (perbedaan 1,34 \%). Defleksi balok komposit dengan UNP stud dan steel headed stud adalah $0.478 \mathrm{~mm}$ dan 0,435 $\mathrm{mm}$ (perbedaan 8,99\%).
\end{abstract}

Kata Kunci: Balok Komposit, Elemen Hingga, Kanal, Paku Berkepala, Penghubung Geser.

\begin{abstract}
Shear connectors or studs have an important role in producing the behavior of steel-concrete composite. There are two recommended types of studs, namely steel headed stud and UNP stud. This study analyzes the comparison of steel-concrete composite beam capacity with steel headed stud and UNP stud. Modeling by using a finite element program is chosen as a method in the analysis of non-linear behavior. The surface area of these two types of shear connectors are designed the same so that nominal strength, number, and distance of installation of the shear connectors will also be the same. The capacity reviewed includes WF steel beam stress, concrete plate stress, studs stress, stresses concentration in WF steel beam and concrete plate, and deflection in composite beams. Before modeling with the finite element program, the design process according to SNI1729:2015 is carried out first to determine the dimensions of the structure to be used. Validation process is required to see the level of modelling accuracy. Method validation is performed by comparing the value of the flexural stress on the bottom and top sides of steel-concrete composite beam. The percentage of modeling reached 86,95\% for the steel headed stud and 87,4\% for the UNP stud. The flexural stress in steel beam with UNP stud and steel headed stud are 19,129 MPa and 19,556 MPa (2,18\% difference). The flexural stress in concrete plate with UNP stud and steel headed stud are 1,21 MPa and 1,194 MPa (1,34\% difference). The composite beam deflection with UNP stud and steel headed stud are 0,478 mm and $0,435 \mathrm{~mm}$ (8,99\% difference). Results show that composite beam with UNP stud has better capacity because it produces smaller values of stresses and deflections.
\end{abstract}

Keywords: Composite Beam, Finite Element, Shear Connector, Steel Headed Stud, UNP.

\section{PENDAHULUAN}

Balok komposit adalah jenis balok yang menggabungkan dua material atau lebih dengan sifat dan karakteristik berbeda namun mampu bekerja sama menjadi satu kesatuan dalam menahan beban yang ada [1]. Balok komposit baja beton mampu mengakomodir kelebihan dari baja maupun beton dalam menahan beban yang bekerja padanya. Struktur komposit memiliki beberapa keuntungan, diantaranya: menghemat profil baja hingga $30 \%$, menghemat tinggi lantai bangunan, mereduksi lendutan pelat lantai, memiliki momen pikul dan kapasitas daya pikul beban yang lebih besar dibandingkan balok konvensional [2].

Balok komposit memiliki kaitan yang erat dengan shear stud atau penghubung geser. Penghubung geser menjadi sangat penting karena merupakan komponen yang menjamin terjadinya sistem komposit antara balok dan baja [3] sehingga tidak ada slip diantara keduanya selama masa layan. SNI 1729:2015 merekomendasikan dua jenis 
penghubung geser, yaitu: steel headed stud atau paku berkepala dan UNP stud atau kanal baja [4]. Stud dipasang diatas flange balok baja yang disambung dengan sambungan las. Dalam mendesain penghubung geser perlu memperhatikan jenis stud, lokasi dan jarak stud, lokasi momen maksimum serta cara pemasanganya karena hal tersebut merupakan faktor yang mepengaruhi terjadinya deformasi pada penghubung geser [5].

Pengujian di laboratorium merupakan metode yang umum dilakukan dalam menganalisis sifat ataupun perilaku dari suatu material karena dirasa paling efektif. Pengamatan dan pengukuran secara langsung dapat meminimalisir kesalahan pengujian dan mempermudah proses analisis. Namun demikian pengujian di laboratorium bukanlah satusatunya metode analisis yang dapat digunakan. Hal ini karena dibutuhkan data pengujian yang banyak untuk mendapatkan hasil pengujian yang akurat. Artinya dibutuhkan waktu, biaya, dan tenaga yang tidak sedikit [6].

Perkembangan teknologi yang pesat menuntut para engineer untuk berinovasi menciptakan ataupun menggunakan suatu perangkat lunak demi kepentingan penelitian. Program bantu analisis struktur digunakan untuk menganalisis elemen makro seperti desain struktur bangunan. Namun untuk analisis elemen mikro hingga kondisi inelastis, program elemen hingga lebih umum digunakan [7]. Berdasarkan penelitian balok baja komposit yang dilakukan oleh Prakash, dkk rasio perbandingan hasil pengujian laboratorium dengan program bantu elemen hingga berkisar antara 0,95 dan 1,03. Ini membuktikan bahwa pemodelan struktur dengan program elemen hingga menghasilkan derajat ketelitian yang sangat baik [8]. Inovasi berbagai program bantu yang ada saat ini tentu saja tidak dapat menggantikan pengujian laboratorium karena terdapat beberapa hal yang tidak dapat dianalisis secara sepihak oleh program bantu [11] namun dirasa mampu meminimalisir waktu, biaya maupun tenaga.

Pada artikel ini penulis melakukan analisis perbandingan kapasitas balok komposit dengan dua jenis penghubung geser yang berbeda. Dua jenis stud tersebut adalah steel headed stud (SHS) yang sudah dilakukan sebelumnya [1] dan UNP stud (UNP). Analisis dilakukan dengan membuat suatu model balok komposit dengan stud menggunakan program bantu elemen hingga. Kapasitas yang ditinjau meliputi distribusi tegangan pada balok baja, pelat beton, dan stud serta defleksi pada balok komposit.

\section{METODE PENELITIAN}

\section{A. Perencanan Dimensi Struktur}

Perencanaan difokuskan pada balok interior dengan bentang $3 \mathrm{~m}$ tanpa menggunakan steel deck. Komponen yang direncanakan meliputi balok baja WF, pelat beton, tulangan baja, pelat pembebanan, pelat tumpuan, dan stud. Balok baja menggunakan profil WF 250.125.5.8 dengan mutu BJ 37. Pelat beton memiliki ketebalan $12 \mathrm{~cm}$ dengan mutu fc' $25 \mathrm{MPa}$. Pelat beton merupakan pelat dua arah yang memiliki tulangan $\mathrm{X}$ dan $\mathrm{Y}$ mutu BJTP 24 dengan pemasangan tulangan $\varnothing 12-175 \mathrm{~mm}$. Lebar efektif balok (bE) adalah $750 \mathrm{~mm}$.

Dalam membandingkan kapasitas SHS dan UNP maka kuat nominal (Qn) keduanya dibuat sama, yaitu sebesar $109.232,996$ N. Hal ini bertujuan agar luas area kedua stud ini sama. Qn dari SHS dan UNP masing-masing dihitung dengan persamaan berikut:

$$
\begin{aligned}
& Q n=0,5 \times \frac{1}{4} \pi d^{2} x \sqrt{f^{\prime} c x E c} \\
& Q n=0,3(t f+0,5 t w) \times L c x \sqrt{f^{\prime} c x E c}
\end{aligned}
$$

Dimana d adalah diameter SHS, Ec adalah modulus elastisitas beton, tf adalah tebal flange, tw adalah tebal web, dan Lc adalah Panjang UNP.
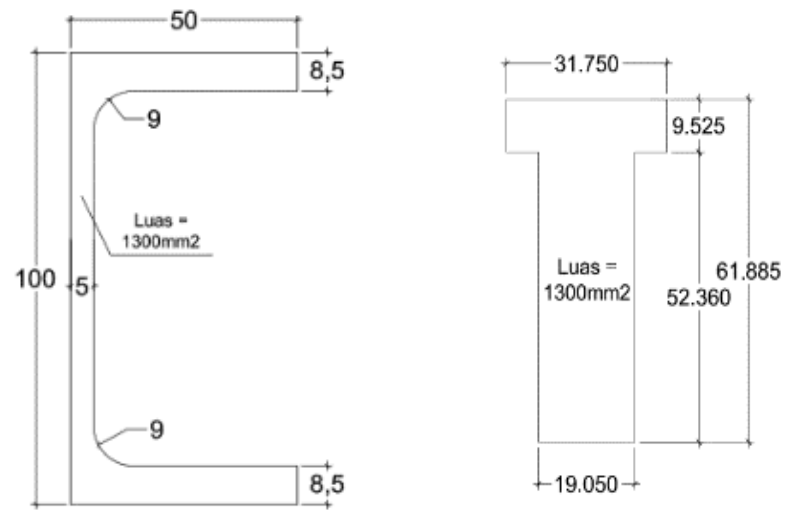

Gambar 1. Geometri UNP Stud dan Steel Headed Stud

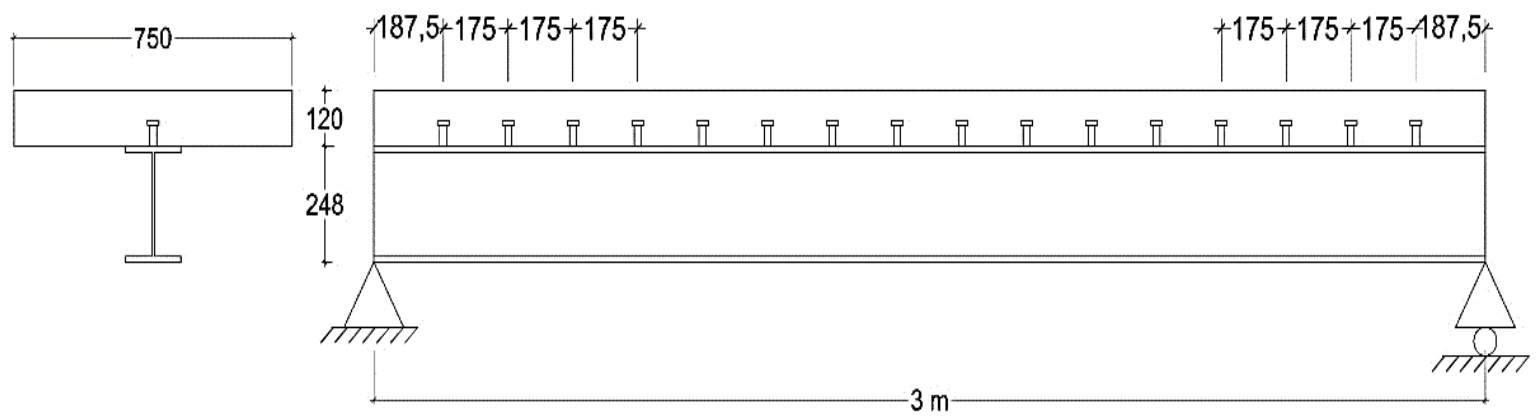

Gambar 2. Model Balok Komposit Baja Beton dengan Steel Headed Stud dan UNP Stud

Satu bentang balok komposit terdiri dari 16 buah stud dengan jarak antar stud $175 \mathrm{~mm}$ dan jarak ke tepi balok $187,5 \mathrm{~mm}$. Pada satu potongan melintang hanya dipasang 1 buah stud.

\section{B. Pemodelan Elemen Hingga}

Balok baja, pelat beton, pelat pembebanan, pelat tumpuan, dan stud dimodelkan menggunakan 3D Defromable Continuum (solid) elements sehingga nodal- 
nodal yang dihasilkan lebih banyak dan pemodelan mendekati kondisi real. Baja tulangan dimodelkan dengan 3D wire.

Pada penelitian ini model Concrete Damage Plasticity digunakan untuk memperoleh perilaku non-linier beton. Model ini mengombinasikan kerusakan elastis beton dengan plastisitas tekan dan tarik beton [1]. Prakash, dkk [8] dan Yan, dkk [9] menggunakan tegangan dan regangan tekan beton saat melewati batas elastis berdasarkan persamaan model beton Carreira dan Chu [10].

$$
\sigma_{c}=\frac{f_{c}^{\prime} \beta\left(\varepsilon_{c}-\varepsilon_{c^{\prime}}\right)}{\beta-1+\left(\varepsilon_{c}-\varepsilon_{c^{\prime}}\right)^{\beta}}
$$

Dimana $\sigma_{c}$ adalah tegangan tekan, $\varepsilon_{c}$ adalah regangan tekan, $\quad \varepsilon_{c}{ }^{\prime}=0,00186$, dan $\beta=2,01$.

Tabel 1. Parameter Perilaku Tekan Non-Linier Beton

\begin{tabular}{ccc}
\hline $\begin{array}{c}\text { Regangan } \\
\left(\varepsilon_{c^{1}}\right)\end{array}$ & $\begin{array}{c}\text { Tegangan } \\
\left(\sigma_{c}\right), \mathrm{MPa}\end{array}$ & $\begin{array}{c}\text { Regangan } \\
\text { Inelastis }\end{array}$ \\
\hline 0,000532 & 12,5 & 0 \\
0,002 & 24,932 & 0,001468 \\
0,003 & 22,356 & 0,002468 \\
0,004 & 19,048 & 0,003468 \\
0,005 & 16,250 & 0,004468 \\
0,006 & 14,041 & 0,005468 \\
0,007 & 12,305 & 0,006468 \\
\hline
\end{tabular}

Pada plastisitas tarik beton, tegangan dan regangan tarik meningkat secara linier hingga mencapai kuat tarik ultimitnya, $\mathrm{ft}$, dan selanjutnya menurun secara linier [7]. Parameter tegangan dan regangan dihitung berdasarkan persamaan Carreira dan Chu [10].

$$
\begin{aligned}
& \sigma_{t}=0,77 \times f t^{\prime} \\
& \varepsilon_{t}{ }^{c k}=\varepsilon_{t}-\varepsilon_{o t}{ }^{e l}
\end{aligned}
$$

Dimana $\sigma_{t}$ adalah tegangan runtuh tarik, $\varepsilon_{t}{ }^{c k}$ adalah regangan runtuh tarik, $\mathrm{ft}^{\prime}=1,85 \mathrm{MPa}, \quad \varepsilon_{o t}{ }^{\text {el }}=$ 0,0002 .

Tabel 2. Parameter Perilaku Tarik Non-Linier Beton

\begin{tabular}{ccc}
\hline Regangan $\left(\varepsilon_{t}\right)$ & $\begin{array}{c}\text { Tegangan }\left(\sigma_{t}\right), \\
\mathrm{MPa}\end{array}$ & $\begin{array}{c}\text { Regangan } \\
\text { Runtuh }\end{array}$ \\
\hline 0,000186 & 1,85 & 0 \\
0,000232 & 1,425 & 0,00005 \\
0,000743 & 0,833 & 0,00006 \\
0,00161 & 0,185 & 0,00143 \\
\hline
\end{tabular}

Balok baja WF, pelat pembebanan, pelat tumpuan, dan tulangan baja dimodelkan dengan perfect plasticity. Model ini menggambarkan perilaku baja yang tidak mengalami strain hardening ketika melewati daerah elastis.

Interaksi antar komponen balok komposit perlu direncanakan dengan tepat untuk menjamin agar hasil sesuai dengan kondisi real. Interaksi antara stud dengan balok baja menggunakan Tie Constraint. Interaksi antara pelat beton dengan balok baja WF, stud, pelat tumpuan, dan pelat pembebanan menggunakan model surface-to-surface dengan baja sebagai master dan beton sebagai slave. Sementara itu interaksi anatara baja tulangan dengan pelat beton menggunakan model constraint embedded region. Sesuai dengan kondisi tulangan baja yang tertanam di dalam beton. Pada bagian tengah bentang balok komposit terdapat pelat pembebanan dengan beban Pressure (P) sebesar $10,573 \mathrm{kN}$. Kedua perletakan menggunakan tipe displacement/rotation dengan $\mathrm{U} 1=\mathrm{U} 2=\mathrm{U} 3=0$.

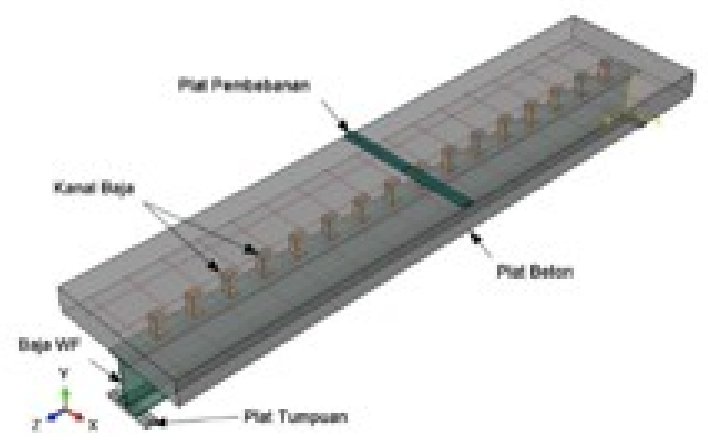

(a)

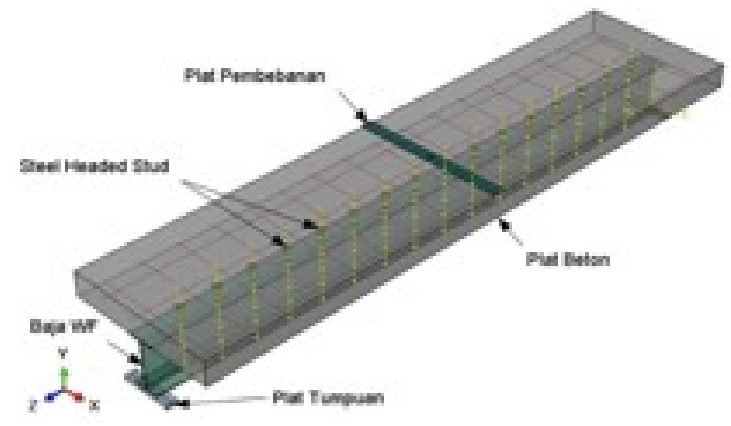

(b)

Gambar 3. Pemodelan Elemen Hingga (a) Steel Headed Stud dan (b) UNP Stud

\section{HASIL DAN PEMBAHASAN}

A. Validasi

Validasi pada penelitian ini dilakukan dengan membandingkan tegangan lentur pada bagian tengah balok komposit hasil perhitungan manual dengan hasil pemodelan elemen hingga. Diperoleh rata-rata rasio untuk SHS dan UNP masing-masing sebesar $86,95 \%$ dan $87,4 \%$.

Tabel 3. Hasil Validasi

\begin{tabular}{cccccc}
\hline & $\begin{array}{c}\text { Manual, } \\
\mathrm{MPa}\end{array}$ & SHS, MPa & $\begin{array}{c}\text { Rasio, } \\
\%\end{array}$ & $\begin{array}{c}\text { UNP, } \\
\mathrm{MPa}\end{array}$ & $\begin{array}{c}\text { Rasio, } \\
\%\end{array}$ \\
\hline $\mathrm{fc}$ & $-1,008$ & $-1,210$ & 83,3 & $-1,194$ & 84,5 \\
$\mathrm{fb}$ & 21,385 & 19,556 & 89,4 & 19,129 & 89,4 \\
\hline
\end{tabular}

$\mathrm{fc}$ adalah tegangan pada serat atas pelat beton dan $\mathrm{fb}$ adalah tegangan pada serat bawah balok baja WF. 
B. Hasil Pemodelan

1. Tegangan

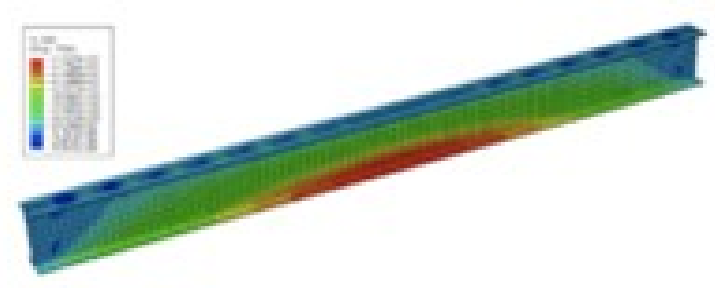

(a)

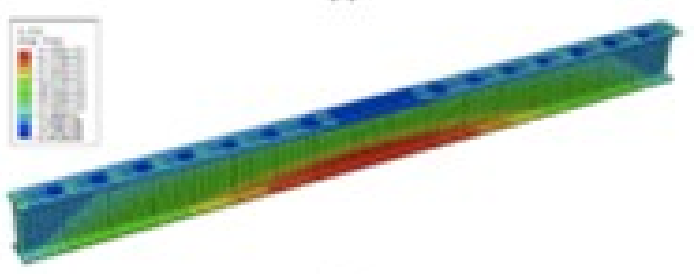

(b)

Gambar 4. Distribusi Tegangan Lentur Balok Baja WF (a) UNP Stud (b) Steel Headed Stud

Gambar 4 menampilkan distribusi tegangan pada balok baja WF. Serat bawah balok baja WF mengalami tegangan lentur positif. Tegangan lentur pada model SHS sebesar 19,556 MPa dan UNP sebesar 19,129 MPa. Perbedaan keduanya sekitar $2,18 \%$. Tegangan lentur maksimum terjadi pada bagian tengah bentang dan semakin mengecil menuju kedua tumpuan ujung.

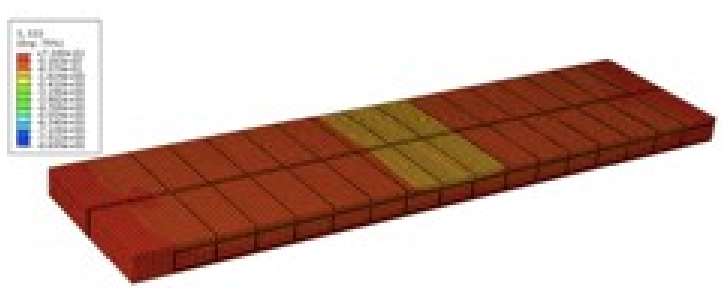

(a)

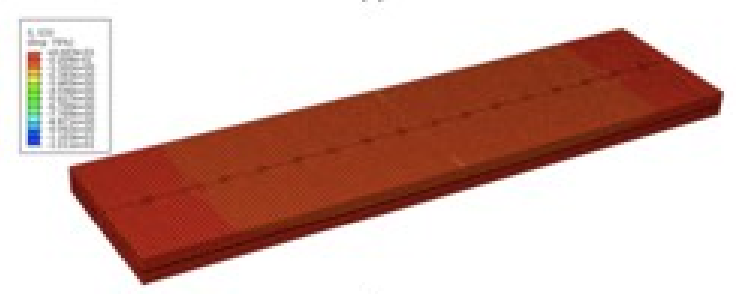

(b)

Gambar 5. Distribusi Tegangan Lentur Pelat Beton (a) UNP Stud (b) Steel Headed Stud

Serat atas pelat beton mengalami tegangan lentur negatif. Pada model SHS sebesar -1,194 MPa dan UNP sebesar -1,21 MPa. Perbedaan keduanya sekitar 1,34\%. Tegangan lentur maksimum terjadi pada bagian tengah bentang dan semakin mengecil menuju kedua tumpuan, namun perbedaannya tidak terlalu signifikan.

Beban yang diberikan merupakan beban Pressure searah gravitasi sehingga menyebabkan terjadinya momen positif. Ini adalah penyebab mengapa tegangan pada balok baja WF merupakan tegangan lentur positif yang nilainya jauh lebih besar dibandingkan dengan tegangan lentur negatif pada pelat beton.

\section{Konsentrasi Tegangan}

Gambar 6 menampilkan kontur konsentrasi tegangan. Konsentrasi tegangan tekan terjadi pada lokasi penempatan stud yang ditunjukkan dengan adanya konsentrasi warna (biru tua) pada flange balok baja WF. Pada balok dengan UNP memiliki konsentrasi tegangan ujung sebesar -5,94 $\mathrm{MPa}$ dan bagian tengah sebesar $0 \mathrm{MPa}$.

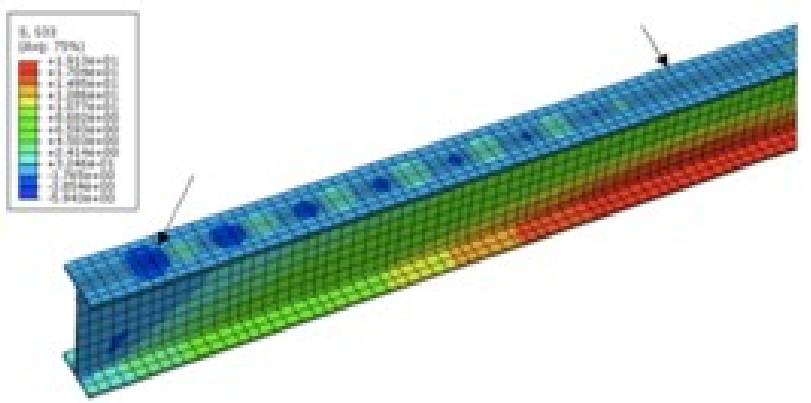

Gambar 6. Konsentrasi Tegangan Balok Baja dengan UNP Stud

Gambar 7 menampilkan konsentrasi tegangan balok baja dengan SHS. Konsentrasi tegangan pada bagian ujung adalah $-6,91 \mathrm{MPa}$ dan semakin mengecil sehingga pada bagian tengah sebesar $-2,79 \mathrm{MPa}$.

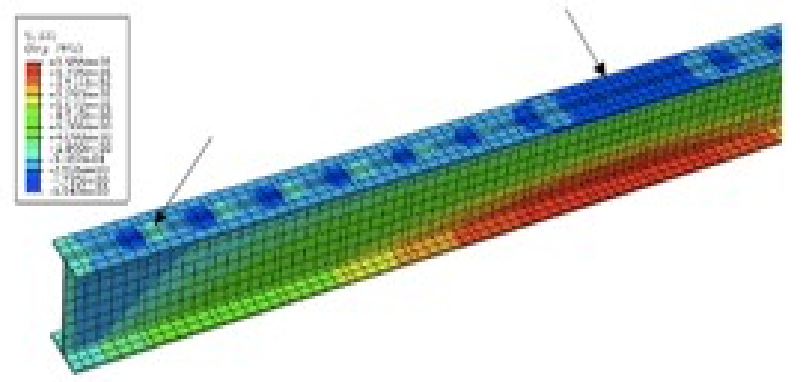

Gambar 7. Konsentrasi Tegangan Balok Baja dengan Steel Headed Stud

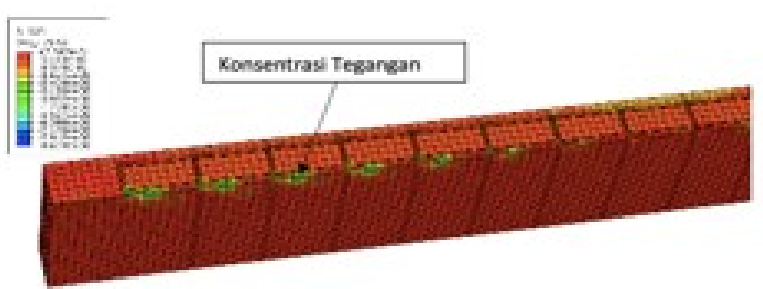

(a)

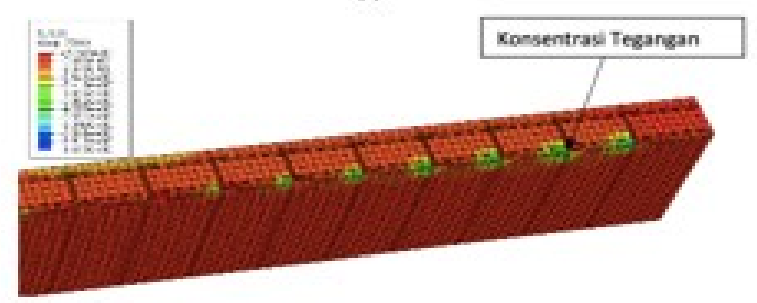

(b)

Gambar 8. Konsentrasi Tegangan Pelat Beton dengan UNP Stud (a) Ujung Kiri dan (b) Ujung Kanan

Gambar 8 memperlihatkan konsentrasi tegangan tekan (warna hijau) pada lokasi penampatan UNP. Berbeda 
dengan konsentrasi tegangan pada balok baja WF, konsentrasi tegangan pada pelat beton dapat diamati dengan membelah bagian tengah penampang. Tegangan terbesar terjadi pada bagiun ujung dan semakin mengecil di bagian tengah betang. Tegangan ujung kanan dan kiri tidak sama, masing-masing sebesar -8,698 MPa dan -6,074 MPa.

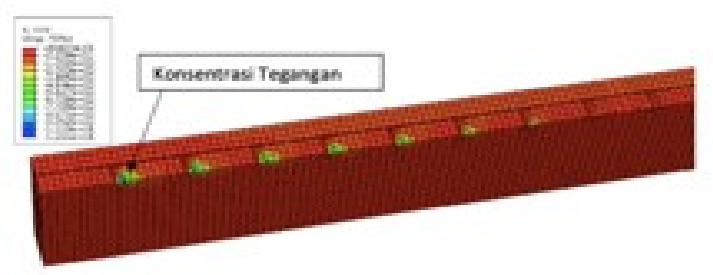

(a)

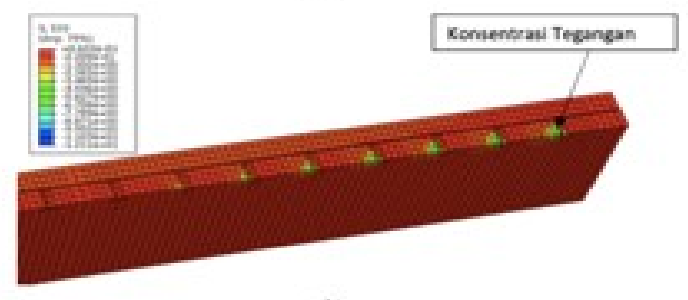

(b)

Gambar 9. Kontur Tegangan Pelat Beton dengan Steel Headed Stud (a) Ujung Kiri dan (b) Ujung Kanan

Pada Gambar 9 terlihat adanya konsentrasi tegangan tekan (warna hijau) pada lokasi penampatan stud. Konsentrasi tegangan terbesar terjadi pada bagiun ujung dan semakin mengecil di bagian tengah betang. Pada balok dengan SHS besar konsentrasi tegangan ujung kanan dan kiri sama besar, yaitu sebesar -12,114 MPa.

Konsentrasi tegangan pada balok baja WF dan pelat beton memiliki kecenderungan yang sama dimana bagian ujung memiliki tegangan yang paling besar. Ini sesuai dengan sifat dari stud yang berfungsi menahan gaya geser yang bekerja pada balok. Gaya geser terbesar terjadi pada bagian ujung balok dan berangsur mengecil pada bagian tengah. Tegangan pada ujung kiri dan ujung kanan balok dengan UNP menjadi tidak sama karena adanya pengaruh arah pemasangan stud.

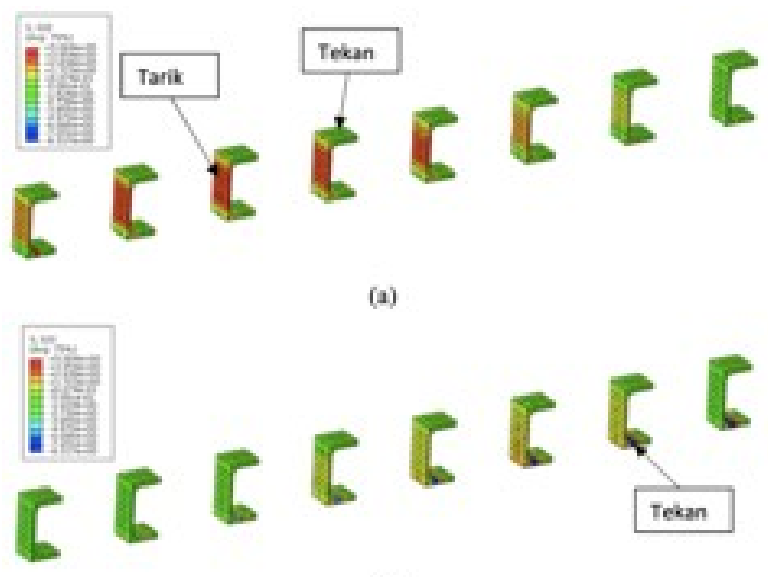

(b)

Gambar 10. Tegangan Geser UNP Stud (a) Bentang Kiri dan (b) Bentang Kanan
Gambar 10 memperlihatkan tegangan geser pada UNP. Jika diperhatikan, stud bentang kiri memiliki tegangan geser yang lebih besar dibandingkan sebelah kanan. Hal ini ditunjukkan dengan adanya warna merah pada web stud di bentang kiri.Tegangan geser terbesar pada bentang kiri adalah $5 \mathrm{MPa}$ sementara pada bentang kanan hanya sebesar $2,3 \mathrm{MPa}$
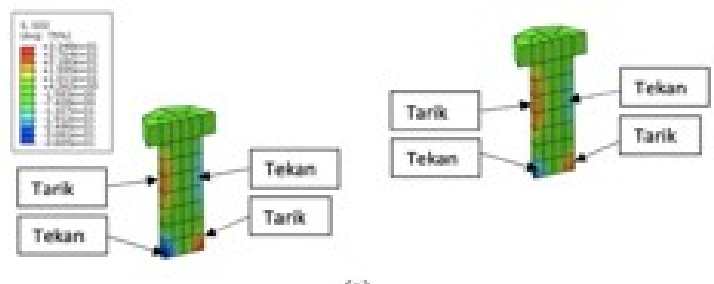

(a)
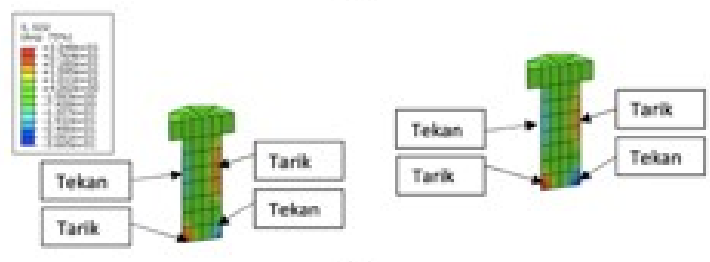

Gambar 11. Kontur Tegangan Geser Steel Headed Stud (a) Ujung Kiri dan (b) Ujung Kanan

Gambar 11 memperlihatkan tegangan geser pada SHS. Jika diperhatikan, stud ujung bentang kiri dan kanan mempunyai distribusi tegangan yang sama, namun berkebalikan (mirroring). Tegangan geser yang terjadi berupa tegangan geser positif dan negatif dimana tegangan geser terbesar adalah 3,34 MPa.

SHS dan UNP menunjukkan perilaku yang sama dimana tegangan geser pada bagian ujung lebih tinggi dan berangsur mengecil pada bagian tengah. Stud berfungsi untuk menahan gaya geser yang bekerja pada balok komposit. Gaya geser terbesar terjadi pada bagian ujung perletakan, ini adalah penyebab mengapa tegangan geser yang dialami oleh stud ujung lebih besar.

Pada balok dengan SHS tegangan geser pada bentang kiri simetris dengan tegangan bentang kanan. Hal ini disebabkan karena kesimetrisan geometri dan posisi pemasangan stud. Lain halnya dengan UNP, tegangan geser pada stud ujung kiri lebih besar dibandingkan dengan ujung kanan. Hal ini karena geometri dari stud jenis ini tidak simetri di segala sisinya sehingga posisi pemasangan stud mempengaruhi besarnya beban yang mampu dipikul.

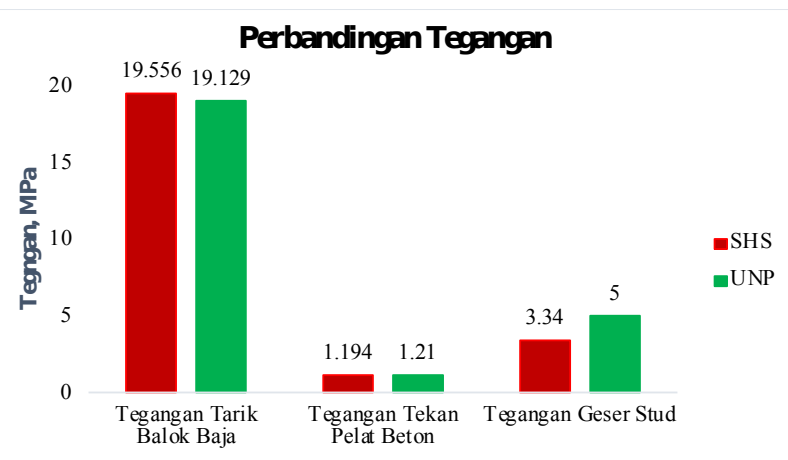

Gambar 12. Perbandingan Tegangan 


\section{Perbandingan Konsentrasi Tegangan}

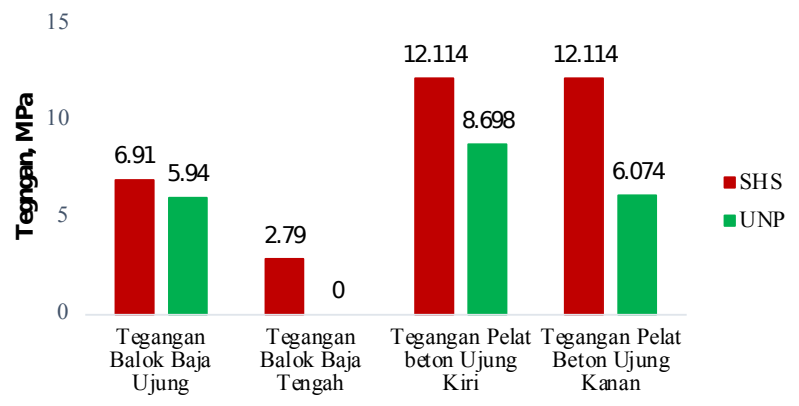

Gambar 13. Perbandingan Konsentrasi Tegangan

Jika ditinjau dari besarnya tegangan yang dialami oleh balok baja WF ataupun pelat beton, UNP lebih efektif dibandingkan SHS karena tegangan yang dialami balok komposit dengan UNP lebih kecil. Lain halnya dengan tegangan yang dialami oleh stud, UNP justru mengalami tegangan geser yang lebih besar. Artinya interaksi antara stud dengan balok baja WF dan beton sangat mempengaruhi. Perlu diingat bahwa sambungan antara stud dengan baja menggunakan las. Pada UNP panjang sambungan las lebih besar dibandingkan SHS. Dengan demikian ikatan antara UNP dengan balok baja WF dan pelat beton akan lebih baik.

\section{Defleksi}

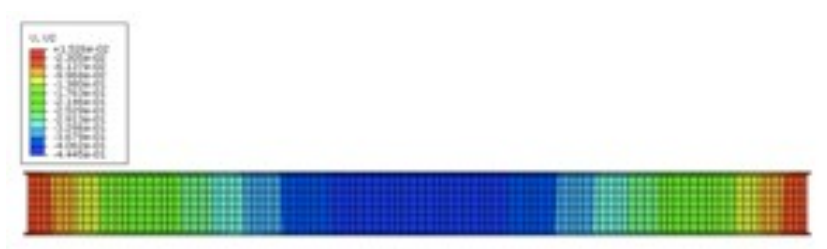

(a)

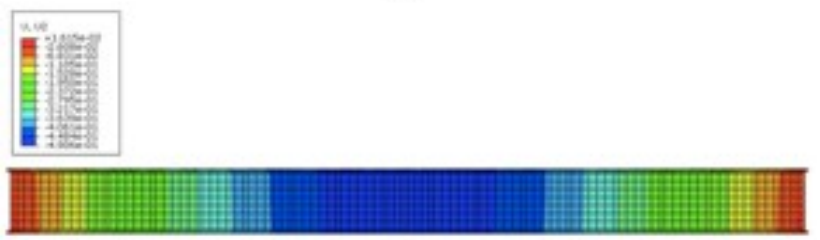

(b)

Gambar 14. Defleksi Balok Komposit (a) UNP Stud (b) Steel Headed Stud

Defleksi yang diamati adalah pada bagian tengah bentang. Balok dengan UNP memiliki deformasi lebih kecil, yaitu $0,435 \mathrm{~mm}$. Sementara balok dengan SHS mengalami defleksi sebesar $0,478 \mathrm{~mm}$ Perbedaan defleksi sebesar 8,996\%. Defleksi yang dihasilkan cukup kecil hal ini dipengaruhi oleh bentangan balok yang dimodelkan. Balok dengan UNP menghasilkan defleksi yang lebih kecil

\section{KESIMPULAN}

Beberapa kesimpulan yang dapat diperoleh dari penelitian ini adalah:

1. Balok komposit dengan UNP memiliki kapasitas yang lebih baik dibandingkan dengan SHS karena menghasilkan nilai tegangan, konsentrasi tegangan, dan defleksi yang lebih kecil.

2. Tegangan yang yang terjadi pada balok baja komposit UNP lebih kecil sebesar 2,18\% dibandingkan dengan SHS.

3. Tegangan yang yang terjadi pada pelat beton komposit UNP lebih kecil sebesar 1,34\% dibandingkan dengan SHS.

4. Konsentrasi tegangan pada bagian ujung balok baja WF dengan UNP lebih kecil 14,04\% dibandingkan dengan SHS. 5. Konsentrasi tegangan pada bagian ujung pelat beton dengan UNP lebih kecil 28,2\% dibandingkan dengan SHS.

6. Defleksi balok komposit dengan UNP memiliki defleksi yang lebih kecil sebesar 8,9\% dibandingkan dengan SHS.

Hal-hal yang dapat disarankan pada artikel ini guna kesempurnaan penelitian selanjutnya adalah perlunya pemodelan interaksi antar komponen struktur yang lebih detail sehingga hasil yang diperoleh bisa lebih mendekati kondisi asli. Selain itu bentangan balok komposit perlu diperbesar agar efek dari pemasangan stud bisa lebih terlihat. Pemodelan beban bolak-balik juga disarankan untuk hasil yang lebih baik.

\section{UCAPAN TERIMA KASIH}

Terima kasih penulis sampaikan kepada Prodi Teknik Sipil Universitas Pertamina dan Prodi Teknik Sipil Universitas Jember sehingga penelitian ini dapat terlaksanan dengan lancar dan tepat waktu.

\section{DAFTAR PUSTAKA}

[1] Hayu, GA. M. Aziz, and S. Arifin, "Analsis Kapasitas Balok Komposit dengan Penghubung Geser Kanal Baja Menggunakan Program Bantu Elemen Hingga," in Proc. Konferensi Nasional Teknik Sipil Ke-13, vol. 1, no. 2, pp. 2-11, 2019.

[2] Rozi, MF, "Pengaruh Panjang Daerah Pemasangan Shear Connector pada Balok Komposit Terhadap Kuat Lentur," Rekayasa Teknik Sipil, vol. 2 no. 2, pp. 1-7.

[3] Dewobroto,W, Struktur Baja: Perilaku, Analisis \& Desain - AISC 2010 Edisi ke-2. Penerbit Jurusan Teknik Sipil UPH, 2016.

[4] SNI 1729:2015. Spesifikasi untuk Bangunan Gedung dan Baja Struktural. Badan Standardisasi Nasional, 2015.

[5] Lahmukang, KM, "Kuat Geser Komposit Baja-Beton dengan Variasi Bentuk Penghubung Geser Ditinjau dari Uji Geser Murni," Jurnal Teknik Sipil,vol. 3, no.1,pp. 45-62, 2014.

[6] Subchan, B, GA Hayu, and E Hidayah, "Analisis Perilaku Efek Retrofit Kolom Beton Berkomposisi Steel Fiber (Engineered Cementitious Composite / Ecc) Akibat Beban Aksial dengan Menggunakan Software Berbasis Finite Element Analysis," Rekayasa Sipil, vol. 13, no.3, pp.207-215, 2019.

[7] Dewobroto, W, Komputer Rekayasa Struktur dengan SAP 2000. Dapur Buku, 2013.

[8] Prakash et al, "Three Dimensional FE Model of Stud Connected Steel-Concrete Composite Girders Subjected to Monotonic Loading," International Journal of Mechanics and Applications, vol. 1, no.1, pp.1-11, 2011. 
[9] Yan, J, Z Li, and J Xie, "Numerical Parametic Studies on Steel-Elastic Concrete Composite Structures, "Jurnal of Constructional Steel Research, vol. 113, pp. 84-96, 2017.

[10] Carreira, DJ, and K Chu, "Stress-Strain Relationship for Reinforced Concrete in Tension," ACI Journal, vol. 83, no. 3, pp. 21-28, 1986.
[11] Sulistiyo, M, GA Hayu, and E Hidayah, "Analisis Sambungan Baut Balok Kolom Rangka Baja Struktural dengan Profil IWF Menggunakan Program Bantu Elemen Hingga," Rekayasa Sipil, vol. 13, no.3, pp.199-206, 2019. 